\title{
Development of Design and Technological Parameters of Ore Extraction for Underground Mining
}

\author{
Igor Savich ${ }^{1}$, Vadim Mustafin ${ }^{1, *}$,Vladislav Romanov ${ }^{1}$, and Dmitriy Sukhov ${ }^{1}$ \\ ${ }^{1}$ Moscow Mining Institute, National University of Science and Technology "MISIS" (NUST MISIS), \\ 109049, Leninsky Ave., Moscow, Russia
}

\begin{abstract}
While defining rational constructive and technological underground mining technique parameters we should consider many factors, especially in caving methods. The experience of exploiting caving technologies shows that the use of traditional designs of this technique is not always efficient and economically expedient. The article presents alternative caving methods, developed by specialists of the department for "Geotechnologies of mineral resources development" of the Moscow Mining Institute, for the conditions of Kola Peninsula polymetallic deposits, chromite deposits of Western Kazakhstan. What is more, we proposed the vector of caving systems development in the deep and high stress mining with difficult geomechanical conditions.
\end{abstract}

\section{Introduction}

Because of various types of mineral deposits with different orebodies morphology, geological conditions and physico-mechanical properties of rocks, we need an individual scientific and engineering approach to select and validate structural and technological parameters of underground mining technique for each specific case. Caving is one of the most complex technologies in terms of determining rational parameters that requires multifaceted analysis in the design process. Currently the share of this technique in Russia and CIS countries is more than $40 \%$, and, according to our estimations, the scale of their use is expected to increase [1].

Among caving methods particular mention should be made of sublevel caving. It has proved its worth in foreign and subsequently domestic practices of ore deposits exploitation. However, the traditional sublevel caving design with Kiruna Mine drawing sections geometry, implemented in several mining industrial enterprises, does not always provide acceptable extraction indicators because the particular qualities of orebodies or their single parts are seldom taken into account. So, we need to improve new designs and technologies in order to increase the cave mining efficiency.

\footnotetext{
* Corresponding author: mustafin vi@,mail.ru
} 


\section{Results and discussion}

One of technological solutions was developed at the department of "Geotechnologies of mineral resources development" of Moscow Mining Institute for inclined and steeply dipping orebodies of copper-nickel deposits in Kola Peninsula. In contrast to Kiruna sublevel caving technique, we developed a variant of production drifts located only in the orebody footwall (Fig.1).

Polymetallic deposits ("Zhdanovskoye", "Tundrovoye", "Bystrinskoye") are represented by reservoir deposits with irregular orebody mineralization and unstable thickness altering in the range 18 to $37 \mathrm{~m}$. The angle of orebodies incidence varies from $15^{\circ}$ to $70^{\circ}$. Orebodies' strike extent is $0,1 \div 2 \mathrm{~km}$, the dip length is $0,8 \div 2,5 \mathrm{~km}$. The deposits are being developed by sublevel caving. The project provides a crosscuts development working. The use of this mining technology has revealed some drawbacks. Specifically, the accepted design solutions do not allow fully working the footwall rich ores out, the ore dilution by waste rocks occurs rapidly and in the result the ore loss increases too. In addition, this caving technique was a relatively large volume of development works.

A distinctive feature of the proposed way from the traditional one is the location of sublevel drifts in the orebody's footwall. According to the results of laboratory small-scale physical models and stochastic granular flow computer simulation, the spatial and constructive parameters alteration makes it possible to reduce the volume of preparatory development operations by 1,000 tons workable reserves, the ore loss and dilution might decrease by 10 percent. The proposed construction concept allows working the footwall rich ores out primarily and with minimal metal losses.

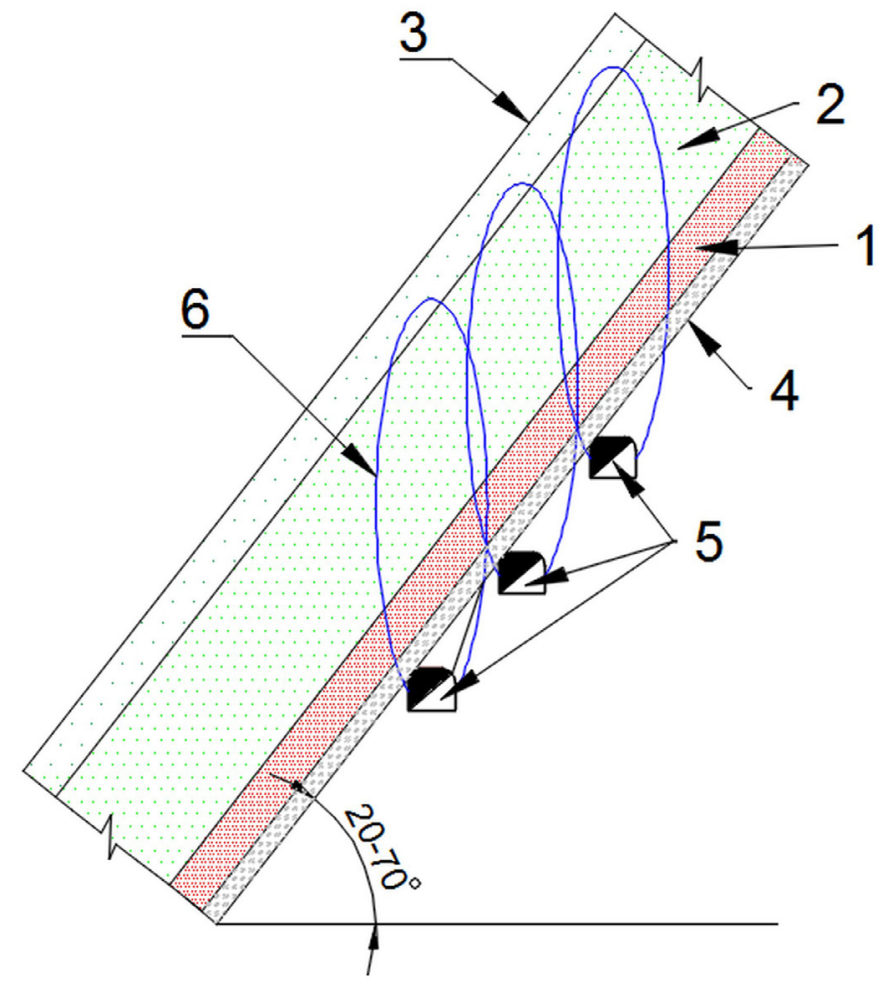

Fig.1. Sublevel caving variant with the orebody footwall drifts for the Kola Peninsula polymetallic deposits (across the strike): 1,2,3 - respectively, ore with high, medium and low content of useful components; 4 - footwall host rocks; 5 - extraction drifts; 6 - draw ellipsoid. 
The basic sublevel cave mining condition is that the draw body form (ellipsoid) should occupy the whole space between horizontal and vertical adjacent drifts [2]. However, mining practice shows that blasting works often result in ore being too crushed. Fragmentation of caved slice is represented by low size particles (no more than $150 \div$ $250 \mathrm{~mm}$ ). Thereby the maximum size of the draw body does not fit in all section volume; it leads to tubular shape flow zone (thinner ellipsoid) and therefore large losses of ore outside the contour of draw ellipsoid [3].

A similar situation happened during the "Voskhod" chromite ore deposit development (Kazakhstan).

An important characteristic of the "Voskhod" deposit was an unstable ore massif which was inclined to small fractional crushing after blasting process (particle size of caved ore $100 \mathrm{~mm}$ ). The geological structure of the deposit included hard lumpy rocks as well as loose fragments and areas with bulk pulverulent rock varieties. In these conditions, the Kiruna sublevel cave technique has led to unsatisfactory production results. The ore extraction percentage was $23.5 \%$ of the sublevel reserves balance.

To solve the problem with the "Voskhod" chromite mine, a modified sublevel caving variant was proposed; the new design provides the displacement of extraction drifts relatively to each other in vertically adjacent sublevels per value not exceeding the draw ellipsoid diameter $\left(\mathrm{D}_{\mathrm{E}}\right)$, calculated with a glance to the accepted sublevel height $\left(\mathrm{H}_{\mathrm{S}}\right)$ (Fig. 2). The level spacing $\left(\mathrm{H}_{\mathrm{L}}\right)$ in this case should be multiple of the number of sublevels. Taking into account the multiplicity of the level and sublevel spacing, the last extraction drift in the first overlying sublevel is coaxial with the extraction drift in the last underlying sublevel.

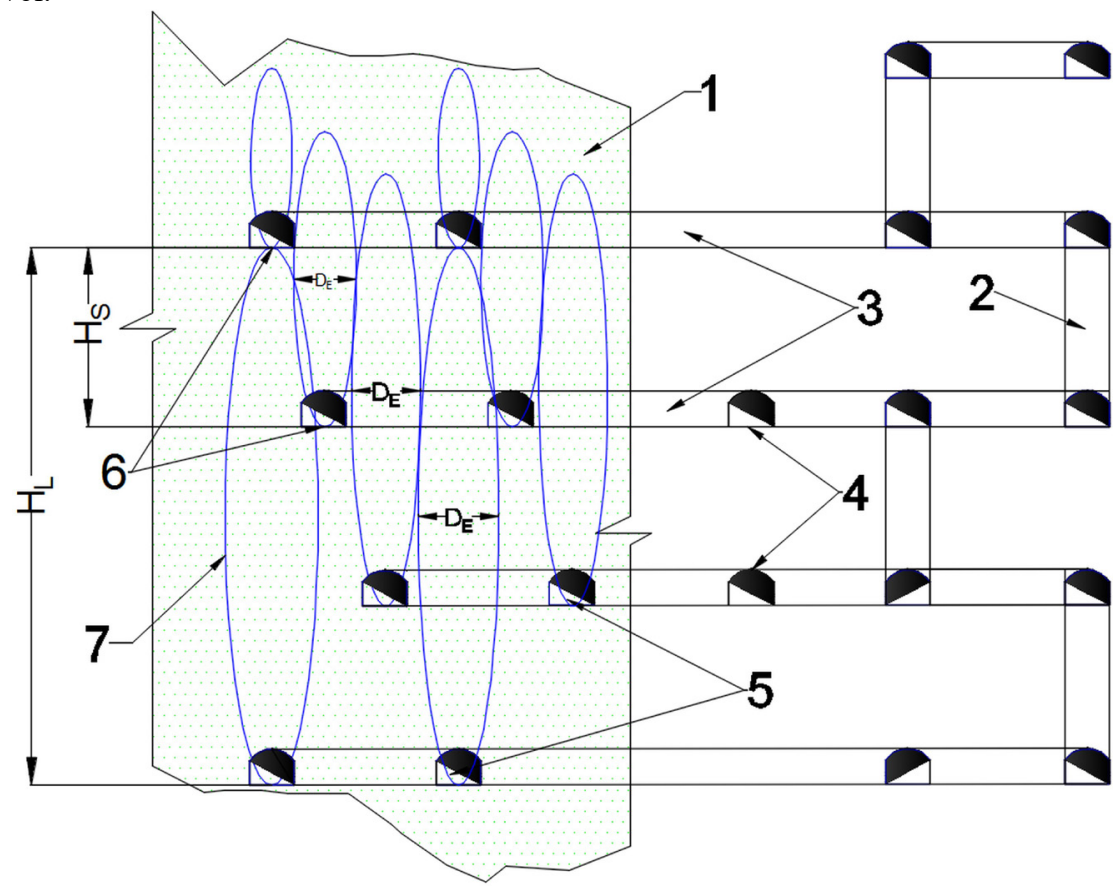

Fig.2. Sublevel caving variant for the small fractional ore development ("Voskhod" chromite mine ): 1 - ore deposit part; 2 - spiral exit; 3 - cross-cut to panel rock drifts; 4 - panel rock drifts; 5 displacement extraction drifts; 6 - adjacent sublevel; 7- draw body (ellipsoid).

The overall reduction of ore losses and dilution occurs due to the convergence of adjacent in the vertical plane extraction drifts (or cross-cuts). 
In constantly deteriorating geological and geomechanical mining conditions caused by the transition to deep and high stress horizons extraction, in our opinion, the improvement of construction and technological solutions in caving mining method should be directed towards increasing the sublevel height and moving to the high block extraction. This will significantly reduce the development works volume, decreasing the rock massif stress and the mine support costs. Nowadays the inducement of high block caving has become possible because of the rapid drilling equipment modernization and the increase of the accuracy of deep blastholes drilling.

The influence of unfavorable geomechanical factors grows with the depth of underground mining. So, the use of the traditional variant of caving technique is limited. In most practices, we need to increase the drift spacing to ensure the stability and safety of extraction operations. However, such measure inevitably leads to unsatisfactory extraction results. In order to avoid this, Moscow Mining Institute developed a new variant of high block caving with multilevel drawing operations (Fig. 3).
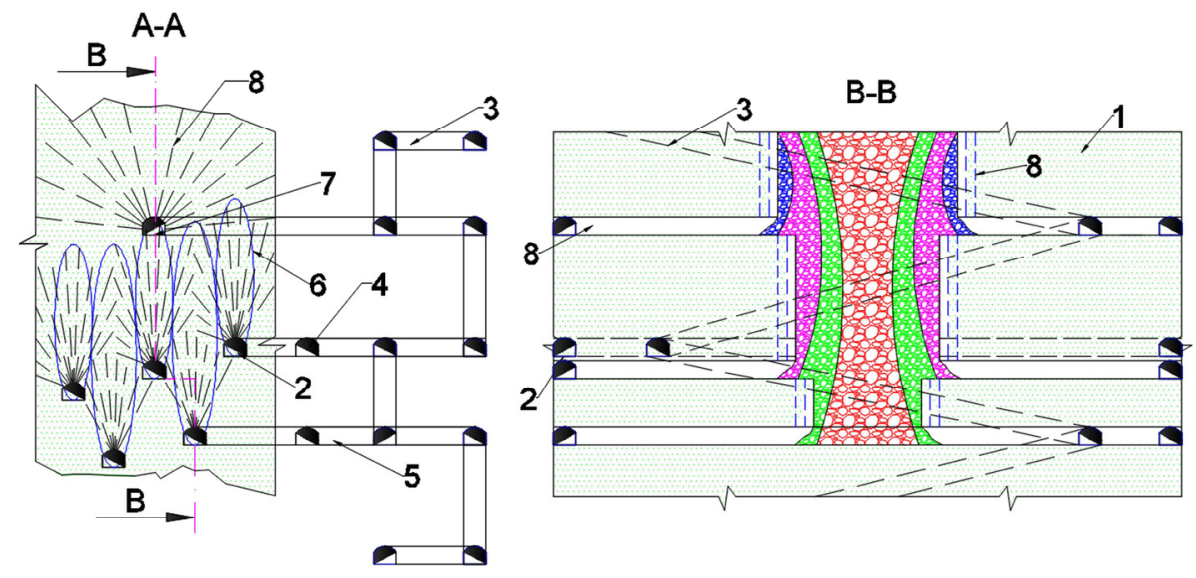

Fig.3. High block caving variant with multilevel drawing operations: 1 - ore deposit part; 2 extraction drifts; 2 - spiral exit; 4 - panel rock drifts; 5- cross-cut to panel rock drifts; 6- draw body (ellipsoid) 7 - drilling drift; 8 - blasthole.

\section{Conclusions}

The proposed designs can be used in underground mines as an alternative to traditional caving techniques. Economic efficiency is ensured by reducing the volume of preparatory development operations, the overall decrease of ore losses and dilution and increased productivity and safety of mining operations.

\section{References}

1. V. Imenitov, Underground mining technique (Nedra, Moscow, 2000)

2. I. Savich, T. Gagiev, V. Mustafin, V. Romanov, D. Sukhov, Min. week symp., 1, 410412 (2015).

3. V. Mustafin, A. Biessikirski, D. Terpák, V. Romanov, D. Sukhov, Inzyn. Miner., 2, 8791 (2017) 